Research Article

\title{
Shear Failure of Bolted Joints considering Mesoscopic Deformation Characteristics of Rock
}

\author{
Yanhui Cheng $\mathbb{D}^{1},{ }^{1}$ Dongliang $\mathrm{He} \mathbb{D}^{1},{ }^{1}$ and Jianyu Yang $\mathbb{D}^{2}$ \\ ${ }^{1}$ School of Civil Engineering, Hunan University of City, Yiyang, Hunan 413000, China \\ ${ }^{2}$ School of Civil Engineering, Changsha University of Science and Technology, Changsha 410114, China \\ Correspondence should be addressed to Jianyu Yang; yangjianyuhu@126.com
}

Received 24 April 2020; Revised 30 May 2020; Accepted 3 June 2020; Published 29 June 2020

Academic Editor: Yixian Wang

Copyright (C) 2020 Yanhui Cheng et al. This is an open access article distributed under the Creative Commons Attribution License, which permits unrestricted use, distribution, and reproduction in any medium, provided the original work is properly cited.

In rock engineering of the cold region, there are a lot of rock joints. The shear characteristics of joints play a decisive role in the stability of rock engineering in the cold area. In this paper, based on the numerical simulation method of particle flow, reasonable microscopic parameters are selected for the numerical simulation of the direct shear test of bolted joints. The results show that the shear stiffness and contact modulus are linearly and positively correlated. The greater the contact modulus, the greater the residual stress, the better the synergetic effect between rock and bolt, and the more developed the microcrack. The smaller the contact stiffness ratio, the greater the residual stress. The shear stiffness decreases with the increase in the contact stiffness ratio, and the larger the contact stiffness ratio, the slower the shear stiffness decreases, while the shear strength does not change with the contact stiffness ratio. The contact stiffness ratio has a weak effect on the number of cracks in the model. The shear stiffness increases with the increase in the parallel bond modulus, and the shear strength decreases with the increase in the parallel bond modulus. The binding stiffness is independent of the shear stiffness, and the peak shear stress decreases with the increase in the binding stiffness ratio. The greater the bond stiffness ratio, the greater the number of cracks.

\section{Introduction}

There are various types of geological defects and discontinuities, such as faults, joints, slices, and unconformities. To a large extent, the movement and deformation of rock mass are mainly subject to these discontinuities, which have a controlling influence on the stability of rock mass engineering [1-5]. For a long time, in order to facilitate the research, rock mass is often idealized as a uniform continuous medium [6-11] in the research of exploring the mechanical properties of rock mass, and the theory describing the deformation and failure process of rock mass is the macroscopic elastic-plastic theory. Such a theoretical model has a certain significance for the research on the mechanical properties of rock mass [12-17]. The laboratory test is the main method to study jointed rock mass $[16,18-21]$. Based on mass shear tests, Barton [22] proposed a JRC-JCS model for estimating the shear strength of rock joints. Lee et al. [23] studied and discussed in depth the characteristics of shear deformation, failure mechanism, and attenuation law of strength of specimens subjected to cyclic shearing. Jiang et al. [24] studied the influence of joint roughness on shear mechanical characteristics. Ghazvinian et al. [25] studied the variation rules of peak shear strength and shear strength of different sawtooth joints. Jahanian and Sadaghiani [26] studied joint shear curves and peak shear strength at different undulation angles. With the development of computer technology and the appearance of a large computer, the numerical simulation method is more and more abundantly used to study the mechanical properties of the rock [27-31]. Numerical methods for studying the mechanical properties of the rock mass, such as particle flow code (PFC), have been widely used in the design and construction of rock mass engineering [32-35]. Park and Song [36] carried out a series of direct shear tests of joints based on PFC3D and studied the effects of geometric 
characteristics and microscopic properties of joints on joint shear performance.

The relationship between shear mechanical characteristics of jointed rock mass and normal stress and joint surface topography has been studied from a variety of perspectives [37-40]. However, it is not enough just to fit the mechanical properties of the rock mass from the macroscopic phenomenon without studying the intrinsic nature of the mechanical properties produced by rock mass. At present, there are few studies on the variation rules of shear mechanical characteristics of bolted jointed rock mass under different rock microscopic parameters $[41,42]$. Due to the difficulties in obtaining and researching methods and means of bolted joint samples with different microscopic parameters, this paper adopts the PFC numerical calculation method to study in detail the effects of different microscopic parameters on the macroscopic shear mechanical behavior of jointed rock mass and the development and evolution characteristics of microcracks. The research conclusion has a certain reference value for the laboratory test.

\section{Modelling and Parameter Calibration}

2.1. Numerical Model. The numerical model is composed of homogeneous particles which are linked by parallel bonding [43-46]. In the parallel bond contact model, the bond is equivalent to a number of springs acting side by side, which can transmit both force and torque and which is more in line with the mechanical properties of rock materials, and it is the most widely used model to simulate the mechanical properties of the rock. The final model is established in this paper. The direct shear boundary conditions and particle generation are shown in Figure 1.

Different from other methods of continuum analysis, the simulation of the macroscopic mechanical behavior of the particle discrete element model must be constructed by assigning values to a series of mesoscopic parameters related to material properties [47-51]. The selection of model mesoscopic parameters is related to the accuracy of the final simulation results. For the microscopic parameters of the particle flow model of rock materials, it is usually necessary to select the macroscopic mechanical parameters (shear mechanical parameters and elastic modulus) and the stressstrain relationship in the laboratory physical tests [52]. In this paper, the macroscopic shear mechanical behavior of jointed rock mass under different joint microparameters is studied. Relevant physical and mechanical parameters obtained through laboratory tests are shown in Table 1. The microscopic parameters of rock were obtained through repeated debugging, as shown in Table 2. The peak shear strength of the rock and joints obtained by numerical calculation and the laboratory test was further compared by about 150 times, and the corresponding shear strength parameters, adhesive force and friction angle, were obtained through the Mohr-Coulomb criterion fitting [53-55], as shown in Table 3, indicating that the values of the two are relatively consistent.

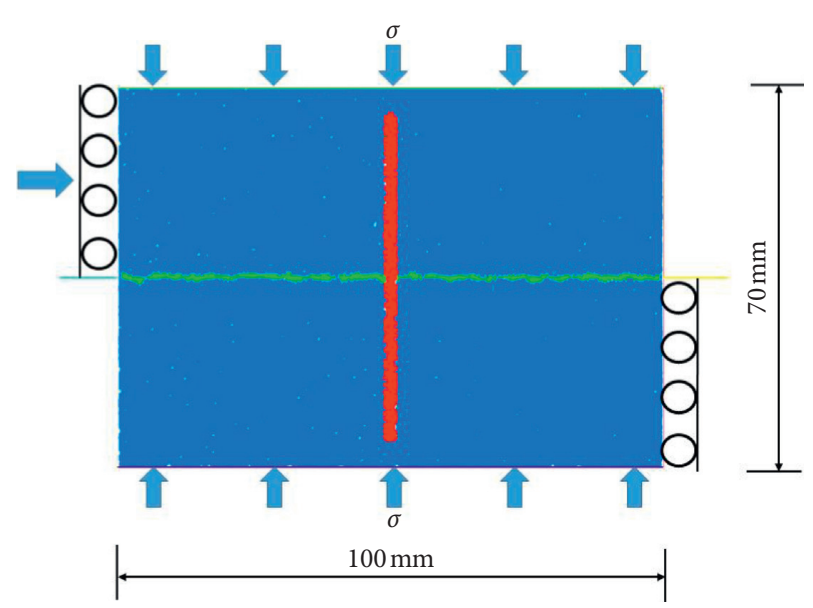

FIgURE 1: Numerical model.

\section{Influence of Rock Mesoscopic Parameters on Macroscopic Shear Mechanical Behavior}

In order to study the influence of rock mesoscopic parameters on the macroscopic shear mechanical behavior of bolted jointed rock mass, the control variable method was adopted to conduct the direct shear test numerical simulation and result analysis for the bolted jointed rock mass specimens with different rock mesoscopic parameters. Without changing other parameters, only the microscopic parameters of the research object were changed to observe the change of the shear mechanical response.

3.1. Contact Modulus. The contact modulus $E^{*}$ is the parameter that controls the elastic modulus of the particle contact. The larger the $E^{*}$ is, the greater the elastic modulus of the particle contact is. The contact modulus $E^{*}$ can be combined with the contact stiffness ratio $k^{*}$. By obtaining the contact area conversion between the two particles, the normal stiffness $\mathrm{kn}$ and tangential stiffness ks of the two particles can be obtained, respectively. Only the contact modulus $E^{*}$ was changed, which was set as $0.1,0.3,1$, and 3 $(\mathrm{GPa})$, respectively. The shear deformation curve of the bolted jointed rock mass was obtained, as shown in Figure 2. By analyzing the elastic modulus corresponding to different contact modulus, the shear stiffness and shear strength corresponding to different contact modulus are obtained, as shown in Table 4 and Figure 3. Although in general, the contact modulus and the shear strength increase, the contact modulus has a major impact on the stiffness of the model, so only the relationship between the contact modulus and the shear stiffness is emphatically analyzed.

Since the contact modulus $E^{*}$ mainly controls the elastic modulus between particle contacts, the larger the $E^{*}$ is, the harder the lithology is. It can be seen from Figure 2 that the slope of the linear segment of the shear stress-shear displacement curve increases with the increase in the contact modulus. From Figure 3, it can be seen that the relationship between shear stiffness and contact modulus is also basically linear. The larger the contact modulus, the greater the rock 
TABLE 1: Mechanical parameters of rock samples.

\begin{tabular}{lccccc}
\hline $\begin{array}{l}\text { Uniaxial compressive strength } \\
(\mathrm{MPa})\end{array}$ & $\begin{array}{c}\text { Tensile strength } \\
(\mathrm{MPa})\end{array}$ & $\begin{array}{c}\text { Cohesion } \\
(\mathrm{MPa})\end{array}$ & $\begin{array}{c}\text { Friction angle } \\
\left({ }^{\circ}\right)\end{array}$ & $\begin{array}{c}\text { Modulus of elasticity } \\
(\mathrm{GPa})\end{array}$ & $\begin{array}{c}\text { Poisson's } \\
\text { ratio }\end{array}$ \\
\hline 18.97 & 1.64 & 1.84 & 58.47 & 2.20 & 0.2 \\
\hline
\end{tabular}

TABle 2: Particle microscopic parameters.

\begin{tabular}{lcc}
\hline Parameter types & Mesoscopic parameters & Value \\
\hline & Grain density $\rho\left(\mathrm{kg} \cdot \mathrm{m}^{-3}\right)$ & 2020 \\
0.10 & 1.6 \\
& Porosity $P$ & $0.4 \sim 0.6$ \\
Basic particle parameters & Particle size ratio $R_{\max } / R_{\min }$ & 3.0 \\
& Particle radius $R_{\max } \sim R_{\min }(\mathrm{mm})$ & 1.5 \\
& Contact modulus $E_{c}(\mathrm{GPa})$ & 5.5 \\
\hline & Stiffness ratio $k_{n} / k_{s}$ & 10 \\
Parallel bonding parameter & Coefficient of friction $\mu$ & 2.2 \\
& Parallel bonding modulus $\overline{E_{c}}(\mathrm{MPa})$ & 1.6 \\
& Parallel bonding stiffness ratio $\overline{k_{n}} / \bar{k}_{s}$ & 7.0 \\
& Normal strength of parallel bonding $(\mathrm{MPa})$ & \\
& Parallel bonding force $(\mathrm{MPa})$ &
\end{tabular}

TABle 3: Comparison of shear strength parameters obtained from the laboratory test and numerical calculation.

\begin{tabular}{lrr}
\hline & & Rock Mohr-Coulomb parameters \\
\hline Laboratory test & $c(\mathrm{MPa})$ & $\Phi\left({ }^{\circ}\right)$ \\
Numerical calculation & 1.84 & 58.47 \\
\hline
\end{tabular}

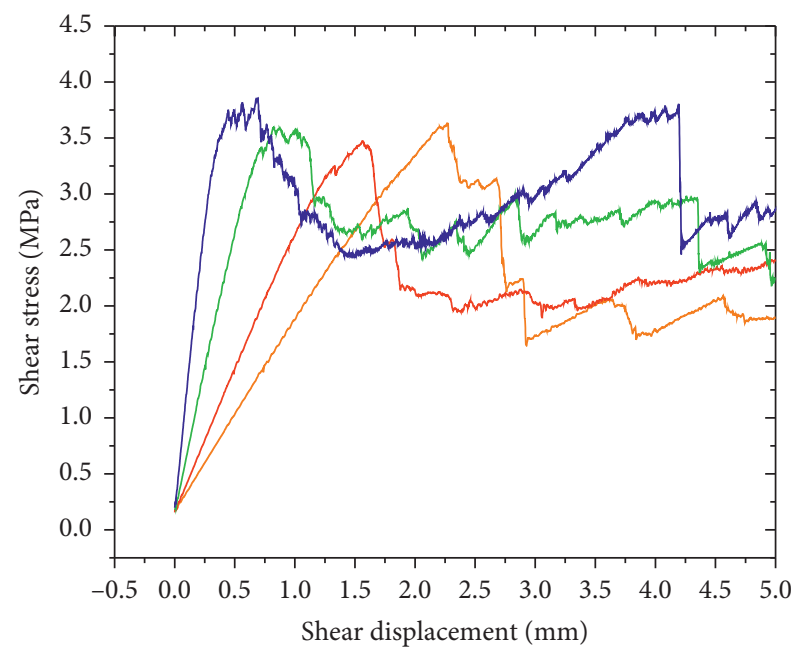

Particle contact modulus $(\mathrm{Pa})$

$\begin{array}{rr}1 \mathrm{e} 8 & -1 \mathrm{e} 9 \\ -3 \mathrm{e} 8 & 3 \mathrm{e} 9\end{array}$

Figure 2: Shear stress deformation curves of bolted joints under different contact modulus.

stiffness and the smaller the shear displacement corresponding to the shear stress peak without changing the other parameters. In addition, the larger the contact modulus $E^{*}$, the greater the postpeak curve fluctuation, the greater the postpeak residual stress, and the better the synergetic effect between rock bolt and rock. The smaller the contact
TABLE 4: Relationship between contact modulus and shear stiffness and peak strength of specimens.

\begin{tabular}{lcc}
\hline Contact modulus $(\mathrm{GPa})$ & $\begin{array}{c}\text { Shear stiffness } \\
\left(\mathrm{MN} / \mathrm{m}^{3}\right)\end{array}$ & Peak strength (MPa) \\
\hline 0.1 & 1.71 & 3.63 \\
0.3 & 2.55 & 3.47 \\
1 & 5.07 & 3.59 \\
3 & 10.63 & 3.85 \\
\hline
\end{tabular}

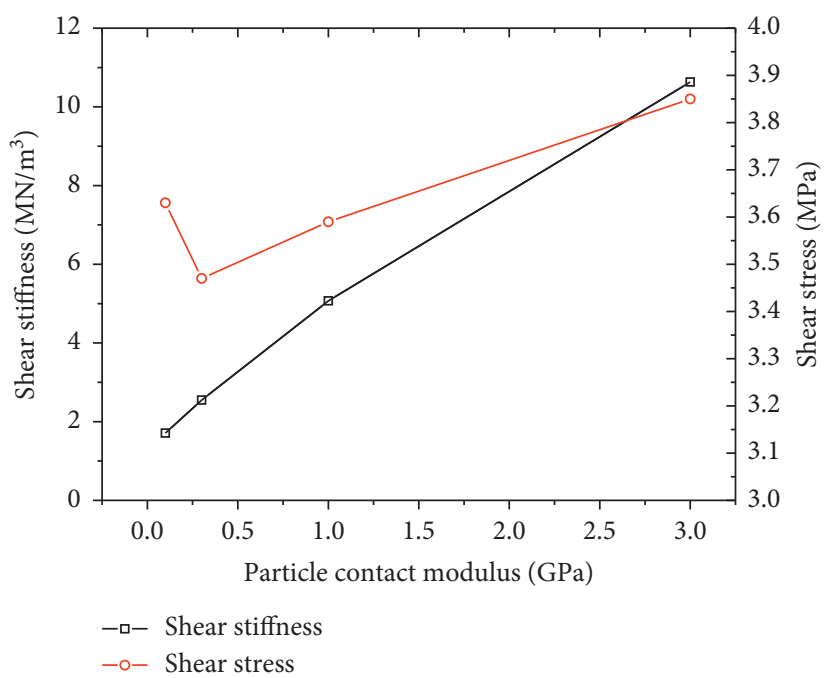

FIgURE 3: Point diagram of the relationship between contact modulus and shear stiffness. 
modulus, the smaller the residual stress. This is because the bolt has a regulating effect on the comprehensive shear stiffness of the structural plane. When the shear modulus of the rock is small, the bolt can increase the comprehensive shear stiffness of the structural plane. When the shear modulus of the rock is large, the bolt can reduce the comprehensive shear stiffness of the structural plane.

3.2. Contact Stiffness Ratio. The contact stiffness ratio $k^{*}$ is the ratio of the normal contact stiffness $\mathrm{kn}$ and the tangential contact stiffness ks in the parallel bonding linear group, namely, $\mathrm{kn} / \mathrm{ks}$, which is a dimensionless quantity. The contact stiffness ratio $k^{*}$ needs to be assigned only when the contact method command is used, and kn and ks can be directly assigned when the contact property command is directly used, so it is not necessary to specify the contact stiffness ratio $k^{*}$. The PFC program uses the contact stiffness ratio $k^{*}$ to automatically calculate the normal stiffness $\mathrm{kn}$ and the tangential stiffness ks of two contact particles in the software through formula (1) and formula (2):

$$
\begin{aligned}
\mathrm{kn} & =\frac{A E^{*}}{L}, \\
\mathrm{ks} & =\frac{\mathrm{kn}}{k^{*}},
\end{aligned}
$$

where $A$ is the contact surface area and $L$ is the distance between the centers of the two particles.

The contact stiffness ratio $k^{*}$ means that the contact modulus $E^{*}$ is used to distribute the normal stiffness $\mathrm{kn}$ and the tangential stiffness ks. The larger the contact modulus $E^{*}$, the larger the normal stiffness and the smaller the ks. The smaller the $k^{*}$ is, the smaller the normal stiffness $\mathrm{kn}$ is and the larger the tangential stiffness ks is. Through the control variable method, only $k^{*}$ was changed, and the contact stiffness ratio $k^{*}$ was set as 0.5 , $1.0,1.5$, and 2.2. The direct shear test was conducted on the structural plane model with bolt and without bolt, and the influence of the contact stiffness ratio $k^{*}$ on the mechanical behavior of the structural plane was observed. The straight shear-simulated shear deformation curve of rock mass with bolted joints is shown in Figure 4. The corresponding shear stiffness and shear strength of each contact stiffness ratio were obtained as shown in Table 5. The relationship between contact stiffness ratio and shear stiffness and shear strength was plotted as shown in Figure 5.

According to the shear deformation curve of bolted joints in Figure 4, the larger the contact stiffness ratio, the smaller the slope of the linear segment before the peak of the curve, that is, the smaller the shear stiffness. The smaller the contact stiffness ratio, the higher the slope of the linear section of the stress deformation curve. This is because the larger the contact stiffness ratio is, the smaller the tangential stiffness ks of the particles will be, and the decreasing tangential stiffness of the particles will reflect the decreasing shear stiffness of the structural plane on the macrolevel. The smaller the contact

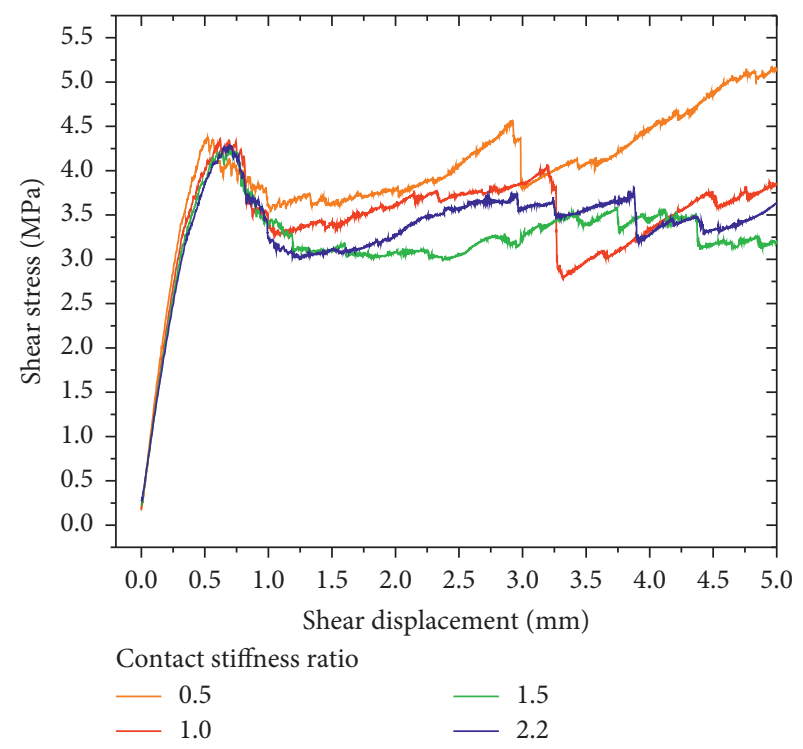

FIGURE 4: Shear deformation curves of bolted and unbolted joints under different contact stiffness ratios.

TABLE 5: Relationship between contact stiffness ratio and shear stiffness.

\begin{tabular}{lcc}
\hline Contact stiffness ratio & $\begin{array}{c}\text { Shear stiffness } \\
\left(\mathrm{MN} / \mathrm{m}^{3}\right)\end{array}$ & Shear strength $(\mathrm{MPa})$ \\
\hline 0.5 & 10.92 & 4.38 \\
1.0 & 10.09 & 4.36 \\
1.5 & 9.59 & 4.22 \\
2.2 & 9.08 & 4.29 \\
\hline
\end{tabular}

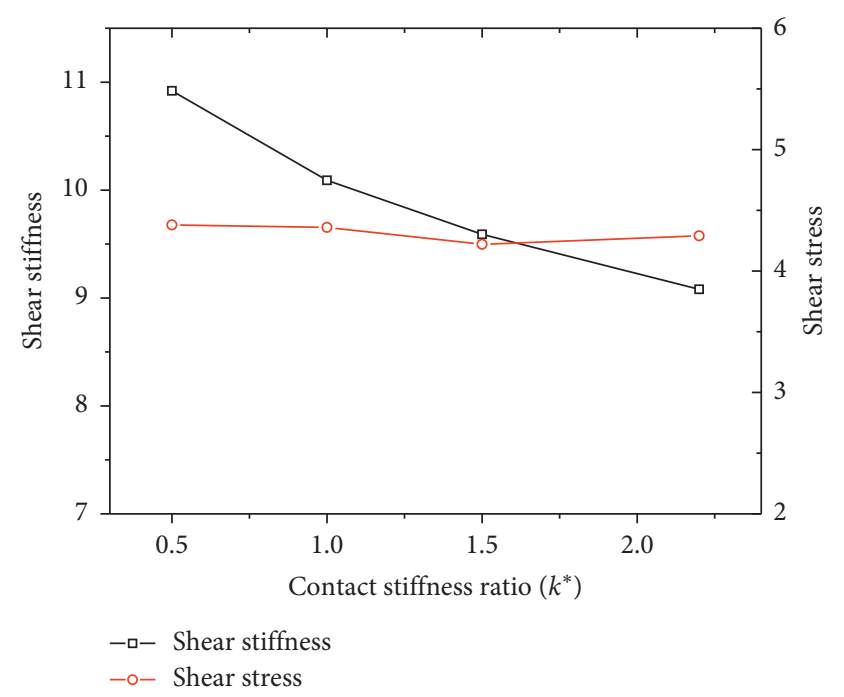

FIgURE 5: Relationship between contact stiffness ratio and shear stiffness.

stiffness ratio, the greater the residual stress and the more obvious the strain hardening characteristics.

It can be seen from Table 5 and Figure 5 that the shear stiffness decreases with the increase in the contact 
stiffness ratio, and the model shear stiffness is negatively correlated with the contact stiffness ratio. The larger the contact stiffness ratio, the slower the shear stiffness decreases, which shows the nonlinear change. The shear strength does not change with the contact stiffness ratio.

3.3. Parallel Bonding Modulus. Parallel bond modulus is the cementation between two particles in each parallel bonding model; the parallel bond modulus is set to be $0.01 \mathrm{GPa}, 0.3$ $\mathrm{GPa}, 3 \mathrm{GPa}$, and $5 \mathrm{GPa}$ while other mesoscopic parameters are kept the same, then the shear deformation of the bolted joint is shown in Figure 6. By analyzing the elastic modulus corresponding to different parallel bond modulus, the shear stiffness corresponding to different contact modulus is obtained, and the relationship between the parallel contact bond modulus, shear stiffness, and shear strength is obtained, as shown in Figure 7.

According to the shear deformation curve of bolted joints in Figure 6, the smaller the parallel bonding modulus is, the smaller the slope of the linear segment before the curve peak is, and the higher the peak strength is, the sharper the curve peak is. The higher the parallel bonding modulus, the higher the slope of the linear segment before the curve peak and the lower the peak strength. The strain hardening occurred after the peak, and the parallel bond modulus increased. When the shear displacement reaches to the vicinity of $4 \mathrm{~mm}$, the four curves experience a sudden decrease in stress of different degrees, which is caused by the sudden embrittlement of the rock bite. The greater the parallel bonding modulus, the greater the stress reduction degree, and the shear displacement corresponding to the stress reduction decreases with the increase in the bonding modulus. It shows that the bond strength remains unchanged; the greater the parallel bond modulus, the smaller the displacement generated by the contact fracture, and the brittleness of the contact bond increases. According to Figure 7 , the relationship between the parallel bonding modulus and shear stiffness and shear strength and the shear stiffness increases with the increase in the parallel bonding modulus, but the increase in the rate of the shear stiffness decreases with the increase in the parallel bonding modulus. The shear strength decreases with the increase in the parallel bond modulus, and the rate of shear strength decreases with the increase in the parallel bond modulus.

3.4. Parallel Bonding Stiffness Ratio. The meaning of parallel bond stiffness ratio $\bar{k}^{*}$ and contact stiffness is similar, the parallel bond stiffness ratio $\bar{k}^{*}$ is the ratio of the stiffness $\bar{k}_{n}$ tothe caking tangential stiffness $\bar{k}_{s}$, namely $\bar{k}_{n} / \bar{k}_{s}$. When the contact method is used, it is needed to assign value for the parallel bond stiffness ratio $\bar{k}^{*}$, PFC software uses formulas (3) and (4) to calculate the bonding stiffness and the tangential stiffness:

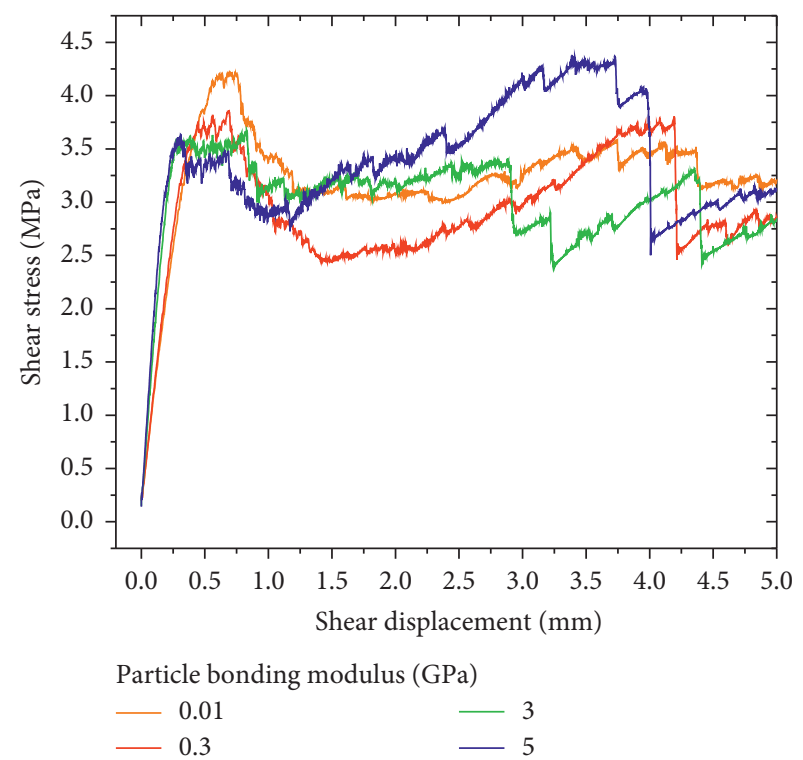

FIGURE 6: Shear stress deformation curves of bolted joints with different parallel bonding modulus.

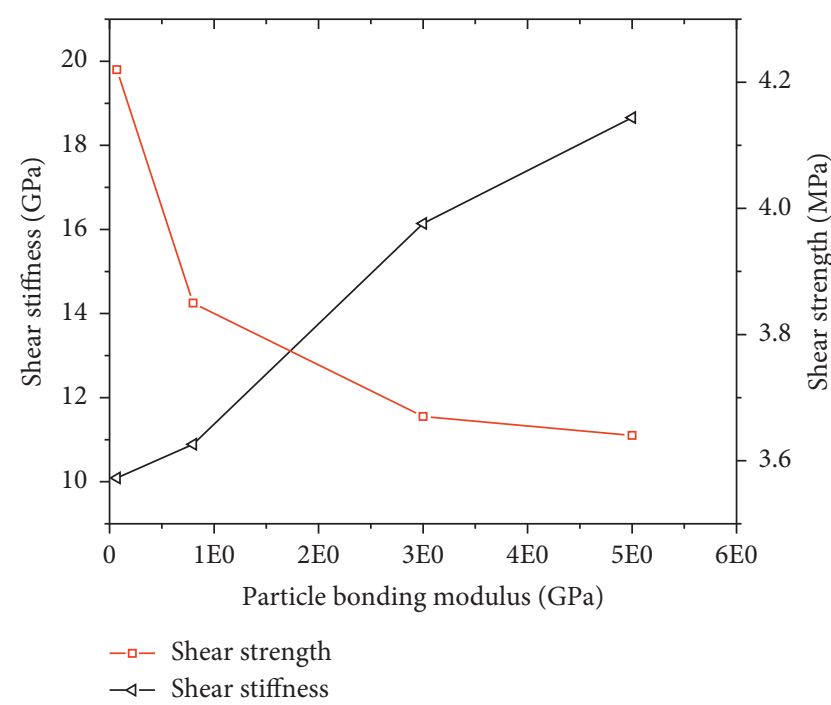

FIGURE 7: Relationship between parallel bonding modulus and shear stiffness and shear strength.

$$
\begin{aligned}
& \bar{k}_{n}=\frac{\bar{E}^{*}}{L}, \\
& \bar{k}_{s}=\frac{\bar{k}_{n}}{k^{*}},
\end{aligned}
$$

where $L$ is the distance between the centers of two particles.

By using the method of control variable to control other mesoscopic parameters as the same, only the parallel bond stiffness ratio $\bar{k}^{*}$ is changed and is, respectively, set to 0.5 , 1.0, 1.5, and 2.2. The peak shear stress corresponding to different bond stiffness ratios is obtained, and the relationship between the bond stiffness ratio and peak shear stress is shown in Table 6. Figure 8 shows that the bond stiffness ratio does not have much effect on the deformation 
TABLE 6: Relationship between bond stiffness ratio and peak shear stress.

\begin{tabular}{lc}
\hline Bond stiffness ratio & Shear strength of bolted joint (MPa) \\
\hline 0.5 & 4.68 \\
1.0 & 4.4 \\
1.5 & 4.32 \\
2.2 & 4.22 \\
\hline
\end{tabular}

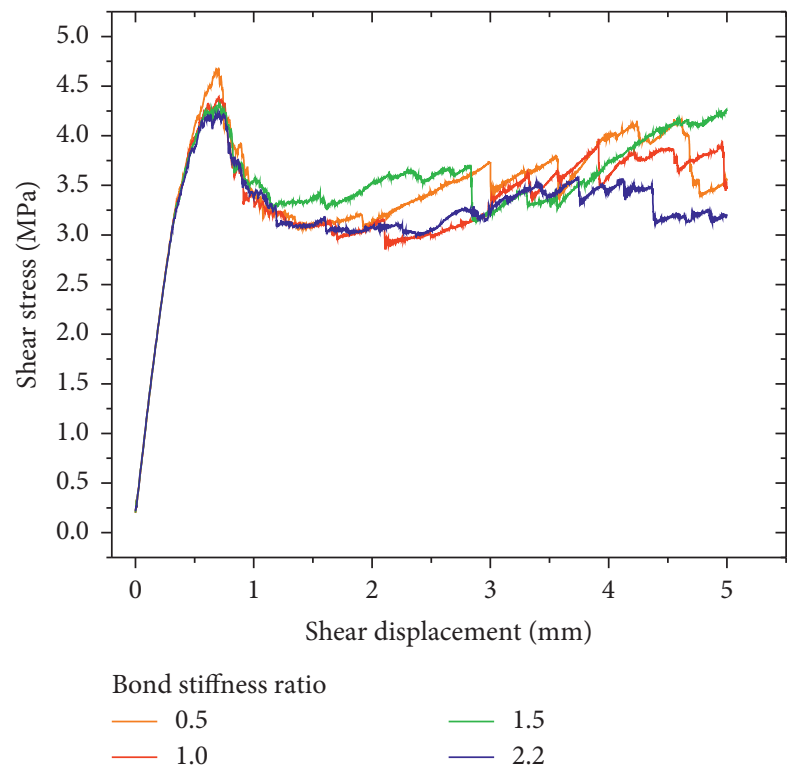

FIGURE 8: Shear stress deformation curves of bolted joints with different bonding stiffness ratios.

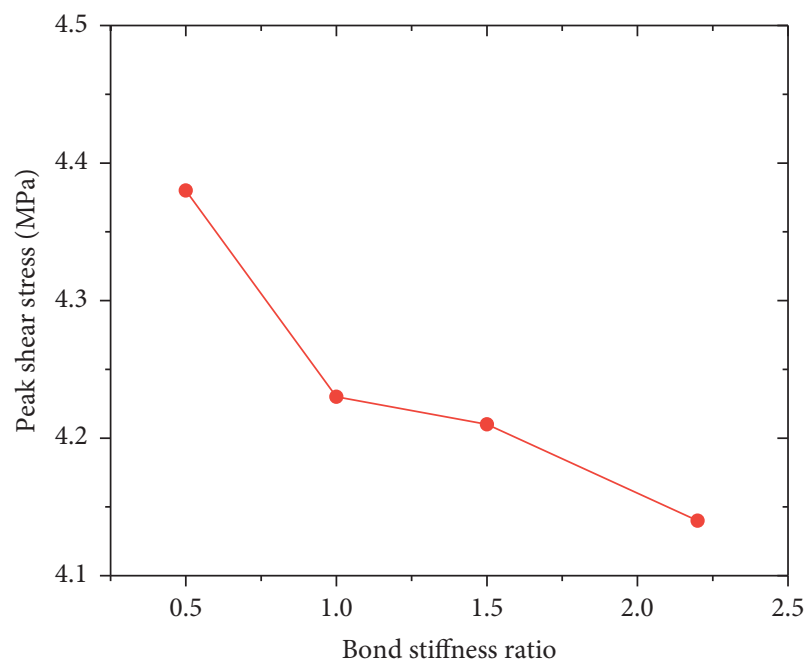

FIGURE 9: Relationship between bond stiffness ratio and peak shear stress.

and stress curve, namely, binder modulus has effect on bonding and tangential stiffness, but almost has no effect on the overall shear stiffness of the model, the stress deformation curves are similar at the elastic stage basic coincidence. As can be seen from the relationship between the bond stiffness ratio and peak shear stress in Figure 9, the peak shear stress decreases with the increase in the bond stiffness ratio, and the decreasing rate of peak shear stress decreases with the increase in the bond stiffness ratio, which tends to be flat. If the bond modulus remains the same, the bond stiffness ratio decreases, that is, the bond tangential stiffness increases. It shows that increasing the tangential stiffness of the bond can affect the shear strength and increase the shear strength.

\section{Conclusions}

(1) Shear stiffness and contact modulus are linearly and positively correlated. The smaller the contact stiffness ratio of bolted joints, the greater the residual stress and the more obvious the strain hardening characteristics. The shear stiffness decreases with the increase in the contact stiffness ratio. The influence of the contact stiffness ratio on the number of cracks in the model is positive, but the correlation is weak.

(2) The shear stiffness increases with the increase in the parallel bond modulus, but the increased rate of the shear stiffness decreases with the increase in the parallel bond modulus. The strain hardening characteristic is enhanced with the increase in the parallel bond modulus.

(3) The peak shear stress decreases with the increase in the bond stiffness ratio, and the reduction rate decreases with the increase in the bond stiffness ratio. The bond stiffness ratio also has an effect on the number of cracks, but the effect is far less than that of the parallel bond modulus.

\section{Data Availability}

The data used to support the findings of this study are available from the corresponding author upon request.

\section{Conflicts of Interest}

The authors declare no conflicts of interest.

\section{Acknowledgments}

This paper was funded by the project supported by the Hunan Provincial Natural Science Foundation of China (2019JJ50031 and 2018JJ2500). The authors wish to acknowledge this support.

\section{References}

[1] S. Xie, H. Lin, Y. Wang et al., "A statistical damage constitutive model considering whole joint shear deformation," International Journal of Damage Mechanics, vol. 29, no. 6, pp. $988-1008,2020$

[2] M. Asadizadeh, M. Moosavi, M. F. Hossaini, and H. Masoumi, "Shear strength and cracking process of non-persistent jointed rocks: an extensive experimental investigation," Rock Mechanics and Rock Engineering, vol. 51, no. 2, pp. 415-428, 2018. 
[3] Y. Zhao, L. Zhang, W. Wang et al., "Creep behavior of intact and cracked limestone under multi-level loading and unloading cycles," Rock Mechanics \& Rock Engineering, vol. 50, pp. 1-16, 2017.

[4] Y. Zhao, J. Tang, Y. Chen et al., "Hydromechanical coupling tests for mechanical and permeability characteristics of fractured limestone in complete stress-strain process," Environmental Earth Sciences, vol. 76, no. 1, p. 24, 2017.

[5] Y. Zhao, L. Zhang, W. Wang, W. Wan, and W. Ma, "Separation of elastoviscoplastic strains of rock and a nonlinear creep model," International Journal of Geomechanics, vol. 18, Article ID 04017129, 2018.

[6] M. Wang, P. Cao, and Y. Chen, "Anisotropy of rock profile JRC values and its empirical formula: a case study on yellow rust granite," Geotechnical and Geological Engineering, vol. 35, no. 4, pp. 1645-1655, 2017.

[7] R.-h. Cao and H. Lin, "Experimental and numerical study of failure behavior and energy mechanics of rock-like materials containing multiple joints," Advances in Materials Science and Engineering, vol. 2017, Article ID 6460150, 17 pages, 2017.

[8] Y. Chen and H. Lin, "Consistency analysis of Hoek-Brown and equivalent Mohr-coulomb parameters in calculating slope safety factor," Bulletin of Engineering Geology and the Environment, vol. 78, no. 6, pp. 4349-4361, 2019.

[9] R. Yong, J. Ye, S.-G. Du, H. Zhang, L. Gu, and H. Lin, "A dice similarity measure for TBM penetrability classification in hard rock condition with the intuitionistic fuzzy information of rock mass properties," European Journal of Environmental and Civil Engineering, vol. 23, pp. 1-16, 2019.

[10] R.-h. Cao, P. Cao, H. Lin, G. Ma, and Y. Chen, "Failure characteristics of intermittent fissures under a compressiveshear test: experimental and numerical analyses," Theoretical and Applied Fracture Mechanics, vol. 96, pp. 740-757, 2018.

[11] T. Liu, P. Cao, and H. Lin, "Damage and fracture evolution of hydraulic fracturing in compression-shear rock cracks," Theoretical and Applied Fracture Mechanics, vol. 74, pp. 5563, 2014

[12] S. Xie, H. Lin, Y. Chen, R. Yong, W. Xiong, and S. Du, “A damage constitutive model for shear behavior of joints based on determination of the yield point," International Journal of Rock Mechanics and Mining Sciences, vol. 128, p. 104269, 2020.

[13] P. Štefane, S. Naib, S. Hertelé, W. De Waele, and N. Gubeljak, "Crack tip constraint analysis in welded joints with pronounced strength and toughness heterogeneity," Theoretical and Applied Fracture Mechanics, vol. 103, p. 102293, 2019.

[14] K. Zhang, N. Li, W. Liu, and J. Xie, "Experimental study of the mechanical, energy conversion and frictional heating characteristics of locking sections," Engineering Fracture $\mathrm{Me}$ chanics, vol. 228, p. 106905, 2020.

[15] H. Lin, S. Xie, R. Yong, Y. Chen, and S. Du, “An empirical statistical constitutive relationship for rock joint shearing considering scale effect," Comptes Rendus Mécanique, vol. 347, no. 8, pp. 561-575, 2019.

[16] Y. Zhao, Y. Wang, W. Wang, L. Tang, Q. Liu, and G. Cheng, "Modeling of rheological fracture behavior of rock cracks subjected to hydraulic pressure and far field stresses," Theoretical and Applied Fracture Mechanics, vol. 101, pp. 59-66, 2019.

[17] H. Lin, X. Zhang, R. Cao, and Z. Wen, "Improved nonlinear Burgers shear creep model based on the time-dependent shear strength for rock," Environmental Earth Sciences, vol. 79, no. 6, p. 149, 2020.

[18] Y. Zhao, Y. Wang, W. Wang, W. Wan, and J. Tang, "Modeling of non-linear rheological behavior of hard rock using triaxial rheological experiment," International Journal of Rock Mechanics and Mining Sciences, vol. 93, pp. 66-75, 2017.

[19] K. Li, Y. Cheng, Z. Y. Yin, D. Y. Han, and J. J. Meng, "Size effects in a transversely isotropic rock under brazilian tests: laboratory testing," Rock Mechanics and Rock Engineering, vol. 53, no. 6, pp. 2623-2642, 2020.

[20] C. Zhang, P. Zou, Y. Wang, T. Jiang, H. Lin, and P. Cao, "An elasto-visco-plastic model based on stress functions for deformation and damage of water-saturated rocks during the freeze-thaw process," Construction and Building Materials, vol. 250, p. 118862, 2020.

[21] H. Wang, H. Lin, and P. Cao, "Correlation of UCS rating with schmidt hammer surface hardness for rock mass classification," Rock Mechanics and Rock Engineering, vol. 50, no. 1, pp. 195-203, 2017.

[22] N. Barton, "Shear strength criteria for rock, rock joints, rockfill and rock masses: problems and some solutions," Journal of Rock Mechanics and Geotechnical Engineering, vol. 5, no. 4, pp. 249-261, 2013.

[23] H. S. Lee, Y. J. Park, T. F. Cho, and K. H. You, "Influence of asperity degradation on the mechanical behavior of rough rock joints under cyclic shear loading," International Journal of Rock Mechanics and Mining Sciences, vol. 38, no. 7, pp. 967-980, 2001.

[24] Y. Jiang, B. Li, and Y. Tanabashi, "Estimating the relation between surface roughness and mechanical properties of rock joints," International Journal of Rock Mechanics and Mining Sciences, vol. 43, no. 6, pp. 837-846, 2006.

[25] A. Ghazvinian, M. J. Azinfar, and P. Norozi, "Mechanical response of discontinuities of different joint wall contact strengths," Arabian Journal of Geosciences, vol. 6, no. 11, pp. 4419-4426, 2013.

[26] H. Jahanian and M. H. Sadaghiani, "Experimental study on the shear strength of sandy clay infilled regular rough rock joints," Rock Mechanics and Rock Engineering, vol. 48, no. 3, pp. 907-922, 2015.

[27] H. Chen, X. Fan, H. Lai, Y. Xie, and Z. He, "Experimental and numerical study of granite blocks containing two side flaws and a tunnel-shaped opening," Theoretical and Applied Fracture Mechanics, vol. 104, p. 102394, 2019.

[28] S. Pirmohammad and M. Hojjati Mengharpey, "A new mixed mode I/II fracture test specimen: numerical and experimental studies," Theoretical and Applied Fracture Mechanics, vol. 97, pp. 204-214, 2018.

[29] J. Meng, J. Huang, C. Yao, and D. Sheng, "A discrete numerical method for brittle rocks using mathematical programming," Acta Geotechnica, vol. 13, pp. 283-302, 2018.

[30] J. Meng, J. Huang, S. W. Sloan, and D. Sheng, "Discrete modelling jointed rock slopes using mathematical programming methods," Computers and Geotechnics, vol. 96, pp. 189-202, 2018.

[31] J. Liu and J. Wang, "The effect of indentation sequence on rock breakages: a study based on laboratory and numerical tests," Comptes Rendus Mécanique, vol. 346, no. 1, pp. 26-38, 2018.

[32] H. Lin, H. Yang, Y. Wang, Y. Zhao, and R. Cao, "Determination of the stress field and crack initiation angle of an open flaw tip under uniaxial compression," Theoretical and Applied Fracture Mechanics, vol. 104, p. 102358, 2019.

[33] H. Lin, X. Ding, R. Yong, W. Xu, and S. Du, "Effect of nonpersistent joints distribution on shear behavior," Comptes Rendus Mécanique, vol. 347, no. 6, pp. 477-489, 2019.

[34] M. Jiang, J. Liu, G. B. Crosta, and T. Li, "DEM analysis of the effect of joint geometry on the shear behavior of rocks," 
Comptes Rendus Mécanique, vol. 345, no. 11, pp. 779-796, 2017.

[35] V. Sarfarazi, A. Ghazvinian, W. Schubert, M. Blumel, and H. R. Nejati, "Numerical simulation of the process of fracture of echelon rock joints," Rock Mechanics and Rock Engineering, vol. 47, no. 4, pp. 1355-1371, 2014.

[36] J.-W. Park and J.-J. Song, "Numerical simulation of a direct shear test on a rock joint using a bonded-particle model," International Journal of Rock Mechanics and Mining Sciences, vol. 46, no. 8, pp. 1315-1328, 2009.

[37] W.-c. Fan, P. Cao, and L. Long, "Degradation of joint surface morphology, shear behavior and closure characteristics during cyclic loading," Journal of Central South University, vol. 25, no. 3, pp. 653-661, 2018.

[38] H. Lin, W. Xiong, and Q. Yan, "Modified formula for the tensile strength as obtained by the flattened Brazilian disk test," Rock Mechanics and Rock Engineering, vol. 49, no. 4, pp. 1579-1586, 2016.

[39] R.-H. Cao, P. Cao, X. Fan, X. Xiong, and H. Lin, "An experimental and numerical study on mechanical behavior of ubiquitous-joint brittle rock-like specimens under uniaxial compression," Rock Mechanics and Rock Engineering, vol. 49, no. 11, pp. 4319-4338, 2016.

[40] H. Lin, W. Xiong, Z. Xiong, and F. Gong, "Three-dimensional effects in a flattened Brazilian disk test," International Journal of Rock Mechanics and Mining Sciences, vol. 74, pp. 10-14, 2015.

[41] G. Grasselli and P. Egger, "Constitutive law for the shear strength of rock joints based on three-dimensional surface parameters," International Journal of Rock Mechanics and Mining Sciences, vol. 40, no. 1, pp. 25-40, 2003.

[42] J. Oh, E. J. Cording, and T. Moon, "A joint shear model incorporating small-scale and large-scale irregularities," International Journal of Rock Mechanics and Mining Sciences, vol. 76, pp. 78-87, 2015.

[43] X. Zhou, J. Li, and H. Lin, "Analysis of internal stress distribution and mechanics characteristics of pre-existing cavity in brittle rock under triaxial cyclic loading," Frontiers in Earth Science, vol. 8, 2020.

[44] X. Fan, K. Li, H. Lai, Q. Zhao, and Z. Sun, "Experimental and numerical study of the failure behavior of intermittent rock joints subjected to direct shear load," Advances in Civil Engineering, vol. 2018, Article ID 4294501, 19 pages, 2018.

[45] X. Fan, P. H. S. W. Kulatilake, and X. Chen, "Mechanical behavior of rock-like jointed blocks with multi-non-persistent joints under uniaxial loading: a particle mechanics approach," Engineering Geology, vol. 190, pp. 17-32, 2015.

[46] R.-H. Cao, P. Cao, H. Lin, C.-Z. Pu, and K. Ou, "Mechanical behavior of brittle rock-like specimens with pre-existing fissures under uniaxial loading: experimental studies and particle mechanics approach," Rock Mechanics and Rock Engineering, vol. 49, no. 3, pp. 763-783, 2015.

[47] C. Zhang, H. Lin, C. Qiu, T. Jiang, and J. Zhang, "The effect of cross-section shape on deformation, damage and failure of rock-like materials under uniaxial compression from both a macro and micro viewpoint," International Journal of Damage Mechanics, vol. 20, 2020.

[48] Y. Wang, H. Zhang, H. Lin, Y. Zhao, and Y. Liu, "Fracture behaviour of central-flawed rock plate under uniaxial compression," Theoretical and Applied Fracture Mechanics, vol. 106, 2020.

[49] D. Lei, H. Lin, Y. Chen, R. Cao, and Z. Wen, "Effect of cyclic freezing-thawing on the shear mechanical characteristics of nonpersistent joints," Advances in Materials Science and Engineering, vol. 2019, Article ID 9867681, 14 pages, 2019.

[50] J. Meng, X. Zhang, J. Huang, H. Tang, H. Mattsson, and J. Laue, "A smoothed finite element method using secondorder cone programming," Computers and Geotechnics, vol. 123, Article ID 103547, 2020.

[51] Q. Lin, P. Cao, R. Cao, H. Lin, and J. Meng, "Mechanical behavior around double circular openings in a jointed rock mass under uniaxial compression," Archives of Civil and Mechanical Engineering, vol. 20, no. 1, p. 19, 2020.

[52] P. Cao, Y. Wen, Y. Wang, H. Yuan, and B. Yuan, "Study on nonlinear damage creep constitutive model for high-stress soft rock," Environmental Earth Sciences, vol. 75, p. 900, 2016.

[53] Y.-X. Wang, P.-P. Guo, W.-X. Ren et al., "Laboratory investigation on strength characteristics of expansive soil treated with jute fiber reinforcement," International Journal of Geomechanics, vol. 17, no. 11, Article ID 04017101, 2017.

[54] Y. Wang, H. Lin, Y. Zhao, X. Li, P. Guo, and Y. Liu, “Analysis of fracturing characteristics of unconfined rock plate under edge-on impact loading," European Journal of Environmental and Civil Engineering, vol. 23, pp. 1-16, 2019.

[55] R. H. Cao, H. Lin, Q. Lin, and J. J. Meng, "Failure mechanism of non-persistent jointed rock-like specimens under uniaxial loading: laboratory testing," International Journal of Rock Mechanics and Mining Sciences, vol. 132, Article ID 104341, 2020. 